\title{
Et hätt noch immer jot jejange ...
}

... es ist noch immer gut gegangen, heißt es im kölschen Grundgesetz. Leider sind viele Verantwortliche in Unternehmen in dieser Hinsicht im Herzen Kölner. Was im Alltag oft stimmt und vor übertriebener Sorge bewahren kann, ist beim Umgang mit gesetzlichen Vorschriften nicht empfehlenswert. Viel wurde über die neue Datenschutzgrundverordnung (DSGVO) im Vorfeld geredet. Befürchtungen wurden ausgiebig und teils emotional diskutiert. Dann kam die Einführung und viele dachten, ,ach, wird alles nicht so heiß gegessen, wie es gekocht wird“.

Das ist einerseits nicht ganz verkehrt. Wer bislang die geltenden Vorschriften befolgt hat, ist schon einen großen Schritt weiter als viele andere. Andererseits ist es aber dann doch nicht so, dass sich gar nichts geändert hätte. Eine allzu lässige Haltung kann sich deshalb schnell rächen und sehr teuer werden.

Vielen fehlt es zudem am Bewusstsein dafür, dass Datenschutz und Datensicherheit ganz entscheidend von den Menschen abhängen. Die Illusion, man könne Konformität mit den gesetzlichen Vorschriften quasi als Software-Paket einkaufen, ist immer noch verbreitet. Die beste technische Sicherheit und Konformität nutzt aber nur wenig, wenn die eigentliche Schwachstelle die Mitarbeiter sind.

Sichere Passworte, die dann auf Klebezetteln am Monitor hängen, sind eben alles andere als sicher. Angestellte, denen das Bewusstsein dafür fehlt, dass sie durch das Anklicken einer gefälschten E-Mail große Probleme heraufbeschwören können, sind ein ernstes Risiko. Es ist daher im Interesse aller Unternehmen, ihre Mitarbeiter fit zu machen für die digitalen Zeiten. Gerade solche, die früher wenig mit IT in Berührung kamen. Gleichzeitig sollte man darauf achten, dass man den IT-Affinen sichere, firmeninterne Werkzeuge anbietet, damit keine Schatten-IT entsteht.

Es gibt viel zu tun, schieben Sie es besser nicht auf die lange Bank!

Herzliche Grüße

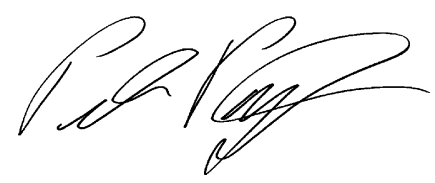

Peter Pagel

Wirtschaftsinformatik \& Management 2019 • 11 (1): 1 https://doi.org/10.1365/s35764-019-00161-1

(c) Springer Fachmedien Wiesbaden GmbH, ein Teil von Springer Nature 2019 